\title{
Leprosy Review Questionnaire
}

In March 2000, a questionnaire was circulated to readers of Leprosy Review. The questionnaire was intended to give our readers the opportunity to comment on the future direction of the journal. A total of 72 replies were received, and the results are briefly summarized below. A full breakdown of the results is available by e-mail (sboobis@aol.com) on request. Thanks to all those who submitted replies; we are still receiving and analysing them, so it is not too late!

\section{Results}

Most of the respondents were aged under 50 years, although eight were aged over 70 years. Approximately $25 \%$ of respondents came from the Indian subcontinent, with large numbers also from Nepal and the UK. Most worked in government leprosy programmes, leprosy NGO programmes, leprosy and TB programmes, research and training institutions. They included 32 clinicians, 22 in management/administration, 12 research scientists and 10 teachers, with small numbers in other categories.

There was an extensive list of qualifications, too many to mention here, but medical degrees constituted the majority; 14 respondents had MSc degrees.

The majority of replies were in favour of continuing to publish Leprosy Review in its present form. Readers wanted an increase in the number of articles on clinical management, but generally did not feel that there should be more emphasis on research.

Approximately $60 \%$ of those replying would be willing to pay more for the Journal to ensure that more original papers could be published. Most were keen to ensure that their institution or organization subscribed to Leprosy Review, but a relatively small proportion wanted to subscribe personally.

The vast majority of those replying wished to see an extension of free distribution of Leprosy Review to workers unable to afford the subscription.

Most of those replying did submit original articles to Leprosy Review, and of those who did not, reasons included no direct involvement in leprosy, no time to write articles, and too few cases to write up.

Three-quarters of respondents stated that Leprosy Review was their first choice when submitting original articles for publication. Reasons for not choosing Leprosy Review included preference for local journals (2), fear of rejection (2), subject matter too leprosy-orientated (3) and time taken to publish too long (2).

Twelve respondents out of 65 had no access to the Internet; of these, only three did not expect to gain access in the near future. Over $75 \%$ of respondents would like to see Leprosy Review published in its entirety on the Lepra website, but in conjunction with the printed publication; only 12 out of 43 respondents wanted the material on the website only. 
Almost three times as many respondents, respectively, had access to their copy of Leprosy Review through their library or institution, or received it free of charge; only 12 of the respondents had a personal subscription to the Journal.

All the respondents read Leprosy Review regularly. The most useful features appeared to be Editorials, Original Articles, Reviews and Case Reports, although it should be said that none of the categories stood out as being particularly unpopular. Of the subject categories, Clinical studies, Epidemiology, Chemotherapy and drug resistance and Prevention of impairment and disability were most popular.

Large numbers of respondents also read the International Journal of Leprosy, Indian Journal of Leprosy, ILEP Newsflash/Medical Bulletin and WHO/TDR News, in addition to a wide variety of other journals. The British Medical Journal and the Lancet were the journals that most respondents also had access to (15 and 9, respectively), although there was a wide variety of both local and international journals. Seven respondents had published in the International Journal of Leprosy. Others were generally local or specialist journals, such as Archives of Ophthalmology.

The most common reason for publishing in other journals was subject matter, or for variety. Only one had previously been rejected by Leprosy Review, and four cited local interest as their reason for favouring other journals.

\section{Conclusions}

Respondents appreciated the clinical content of Leprosy Review, and in general did not want any dramatic changes made to content. They were keen to have access to Leprosy Review on the Lepra website, but not at the expense of the 'paper' journal. There was also a feeling that free distribution of Leprosy Review should be increased. It is very encouraging that so many readers find Leprosy Review useful in their work, and the Editorial Board will continue to work to improve the service that we provide.

Susan Boobis

(Assistant Editor, Leprosy Review)

Postscript. In January of the year, Leprosy Review's Editorial Board voted to publish each issue of the journal on the LEPRA website (http://www.lepra.org.uk). Readers will now be able to access papers of interest on the website. 